\title{
Unique biphasic progestagen profile in parturient and non-parturient giant pandas (Ailuropoda melanoleuca) as determined by faecal hormone monitoring
}

\author{
David C Kersey, David E Wildt, Janine L Brown, Rebecca J Snyder ${ }^{1}$, \\ Yan Huang ${ }^{2}$ and Steven L Monfort \\ Smithsonian Conservation Biology Institute, Center for Species Survival, Front Royal, Virginia 22630, USA, \\ ${ }^{1}$ Zoo Atlanta, Atlanta, Georgia 30315, USA and ${ }^{2}$ China Conservation and Research Centre for the Giant Panda, \\ Wolong Nature Reserve, Wenchuan, Sichuan Province 623006, People's Republic of China
}

Correspondence should be addressed to D C Kersey who is now at College of Veterinary Medicine, Western University of Health Sciences, Pomona, California 91766, USA; Email: dkersey@westernu.edu

\begin{abstract}
The luteal phase of the giant panda has been exclusively assessed by studying urinary hormone patterns in a very few individuals. To better understand hormonal dynamics of protracted progestagen excretion in this endangered species, we monitored hormonal metabolites in the fibrous faeces of multiple females in the USA and China. Giant pandas that were anoestrual during the breeding season excreted baseline progestagen throughout the year. In contrast, there were two distinctive periods when progestagen excretion increased in females that experienced behavioural oestrus, the first being modest, lasting for 61-122 days, and likely reflecting presumptive ovulation. This increase was far surpassed by a secondary rise in progestagen excretion associated with a rejuvenated luteal capacity or hormone production from an extra-gonadal source. The duration of this 'secondary' rise in progestagen excretion averaged $\sim 45$ days and terminated in a decline to baseline coincident with parturition or the end of a non-parturient luteal interval. Data revealed that, even with a complex, biphasic progestagen profile, the longitudinal patterns produced by giant pandas were relatively consistent among animals and across years within individuals. However, progestagen excretion patterns throughout this period could not be used to discriminate among non-pregnant, pregnant or pseudopregnant states.
\end{abstract}

Reproduction (2010) 140 183-193

\section{Introduction}

The reproductive biology of the female giant panda has received considerable attention over the past 30 years (Snyder et al. 2004, Howard et al. 2006, Steinman et al. 2006). Aside from the species' natural charisma, the reproductive biology of the giant panda is intriguing because females are seasonally monoestrus, having the opportunity to conceive during only one $24-72 \mathrm{~h}$ period annually. Because the ex situ population is important as 'insurance' for wild counterparts and as a potential source of animals for future reintroductions (Ellis et al. 2006), there is urgency in ensuring that every animal reproduces, despite the narrow window of fertility. Therefore, individual females are typically monitored intensively during the annual single oestrus to allow accurately timed matings and/or artificial inseminations (Als).

Until recently, endocrine data on the giant panda were largely derived from evaluating hormonal metabolites in urine (Steinman et al. 2006). We recently demonstrated the ability to detect changes in oestrogen and progestagen metabolites in bamboo-laden, fibrous faeces during this species' dynamic perioestrual interval (Kersey et al. 2010). Most previous endocrine studies in giant pandas have focused on behavioural oestrus and ovulation, when there appears to be a modest postovulatory rise in urinary progestagen (usually termed the primary rise; Steinman et al. 2006). There has been little attention directed at understanding the prolonged luteal phase in pregnant versus non-pregnant individuals. Of ten reports on this topic, only three giant pandas in total have been monitored for urinary progestagen profiles from ovulation to parturition or through a non-parturient phase (sometimes referred to as 'pseudopregnancy'; Bonney et al. 1982, Hodges et al. 1984, Chaudhuri et al. 1988, Masui et al. 1989, Monfort et al. 1989, McGeehan et al. 2002, Narushima et al. 2003, Dehnhard et al. 2006, Steinman et al. 2006, Spady et al. 2007). In these cases, a secondary urinary progestagen rise has occurred 74-122 days after the end of oestrus (Steinman et al. 2006) that has suggested a shift in 
hormonal source, perhaps related to nidation. The giant panda has long been considered to experience delayed implantation (Hodges et al. 1984, Monfort et al. 1989, Zhang et al. 2009), a strictly mammalian strategy prominent in carnivores, especially ursids (Hamlett 1935, Conaway 1971, Weir \& Rowlands 1973, Renfree \& Calaby 1981, Mead 1989, Sandell 1990, Lindenfors et al. 2003, Spady et al. 2007). After fertilization, the embryo is sustained as a blastocyst until an unidentified trigger stimulates implantation and resumption of development (Renfree \& Calaby 1981, Mead 1989, Sandell 1990). Although peak in urinary progestagens coincides with ultrasonographic foetus detection in giant pandas (Zhang et al. 2009), it is unknown whether nidation occurs with the onset of a secondary progesterone $\left(\mathrm{P}_{4}\right)$ rise, as has been demonstrated in the mink (Mustela vison; Allais \& Martinet 1978), European badger (Meles meles; Canivenc \& Bonnin 1981) and spotted skunk (Spilogale putorius; Mead 1981). The phenomenon of pseudopregnancy (i.e. when a female experiences the same physiological and behavioural changes as a pregnant counterpart; Erskine 1998) is recognized in other ursids, including a prolonged and elevated progestagen phase with profiles that are indistinguishable from pregnant conspecifics (e.g. American black bear, Ursus americanus; Schulz et al. 2003; Asiatic black bear, Ursus thibetanus; Sato et al. 2001; brown bear, Ursus arctos; Tsubota et al. 1992; sun bear, Helarctos malayanus; Schwarzenberger et al. 2004). A similar prolongation of progestagen excretion occurs in the giant panda, although this method is uninformative in diagnosing pregnancy (Monfort et al. 1989, Steinman et al. 2006).

Given the success of studying the dynamics of perioestrus via faecal monitoring in this species (Kersey et al. 2010), we used the same approach to examine the extended (and largely ignored) post-ovulatory interval. Because faecal assessments in mammalian species generally 'dampen' the hormonal fluctuations usually measured in blood (Monfort 2003, Schwartz \& Monfort 2008), we hypothesized that monitoring progestagens in faeces would provide a more accurate representation of the magnitude and temporal patterns of the primary versus secondary progestagen rise. In this context, we took advantage of giant pandas housed in two zoological collections in North America as well as one of the largest captive breeding centres in China. This unique accessibility allowed the first ever, long-term, comparative assessment of giant pandas that were cycling, anoestrual, pregnant or non-parturient.

\section{Results}

We examined a total of 30 reproductive seasons (range, 1-4 per female) for the 14 giant pandas. Ten were acyclic with no expression of behavioural oestrus or change in baseline faecal progestagen (see below).
On 19 occasions, signs of oestrus were evident, and natural breeding and/or Al occurred. One female demonstrated oestrus, but was not mated or inseminated. Of the giant pandas that were mated and/or Al, 11 became pregnant and gave birth to cubs, whereas the remaining 9 did not give birth and were classified as non-parturient.

\section{Mean luteal faecal progestagen profile}

Figure 1 depicts the mean progestagen pattern from pre-ovulation through the entire luteal phase for all individuals in which a combined primary and secondary hormonal rise was evident. The existence of a primary progestagen elevation was apparent where faecal progestagen concentrations were higher $(P<0.05)$ for the 50-day period after, compared to the 50-day interval before, the urinary $E$ peak $(283.7 \pm 13.5$ vs 215.4 $\pm 15.8 \mathrm{ng} / \mathrm{g})$. The secondary rise $(2289.5 \pm 236.9 \mathrm{ng} / \mathrm{g})$ occurred when progestagen concentrations increased 6.3 -fold $(P<0.05)$ over primary rise concentrations $(360.8 \pm 13.9 \mathrm{ng} / \mathrm{g})$. The initial rise began the day after the urinary $E$ peak and, on average, lasted 88.8 days ( \pm 6.6 days; range $61-122$ days), whereas the shorter $(P<0.05)$ secondary rise lasted 44.7 days ( \pm 3.5 days; range $30-64$ days).

\section{Urinary versus faecal progestagen patterns}

The correlations between matched urine and faecal progestagen patterns for SB473 and SB452 (one cycle each; Fig. 2) were strong $(r=0.80$ and $r=0.62$ respectively; $P<0.05)$. According to our criteria, the total luteal durations for SB473 and SB452 were 13 days longer (149 days) and 7 days shorter (141 days) respectively, using urinary as opposed to faecal evaluations. Duration of the primary rise was 14 days shorter (88 days) in SB473 but not different in SB452 (88 days)

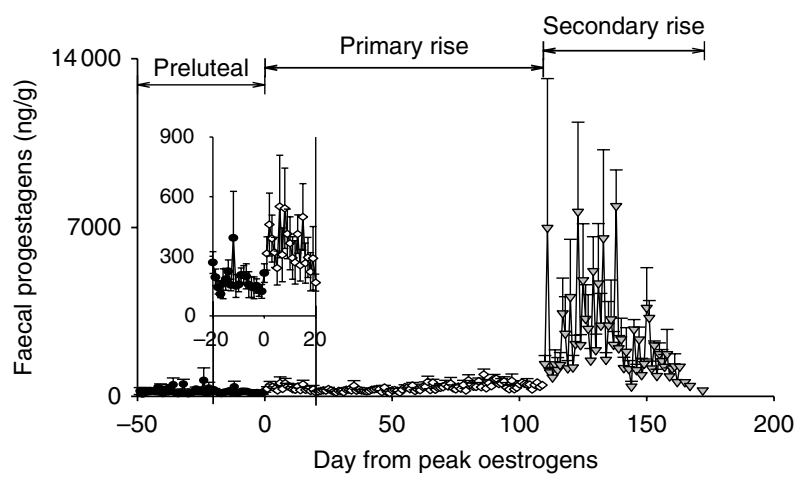

Figure 1 Mean ( \pm S.E.M.) progestagen profile of ten females during the pre-luteal period and primary and secondary rise intervals. Data are aligned to day of peak faecal oestrogen excretion. Scale of inset graph illustrates change in faecal progestagen excretion from preluteal to primary rise concentrations. 


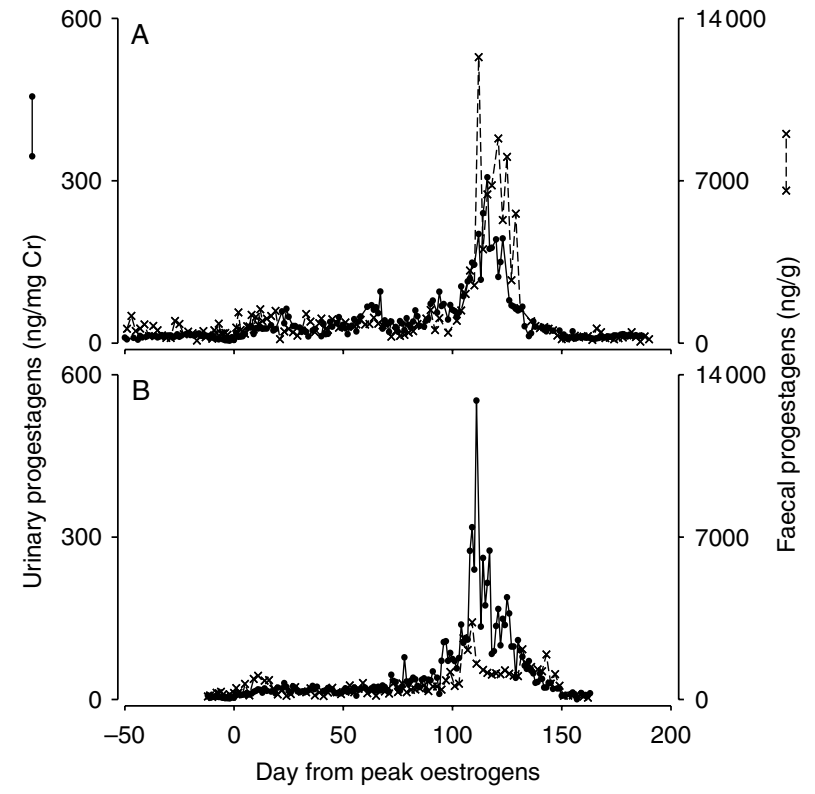

Figure 2 Matched urinary (closed circles, solid lines) and faecal (crosses, dashed lines) progestagen metabolite concentrations from females (A) SB473 and (B) SB452. Data are aligned to day of peak urinary oestrogen excretion.

using urinary versus faecal evaluations. Duration of the secondary progestagen rise was nearly twice the length in SB473 (61 days) but not different in SB 452 (56 days) using urinary versus faecal evaluations.

Repeated annual assessments (each for 3 or more years) of the Smithsonian National Zoological Park (SNZP) and Zoo Atlanta (ZA) females revealed that progestagen concentrations were always lower $(P<0.05)$ during the primary compared to secondary rise interval (faecal measurements are presented in Table 1). However, when urinary versus faecal patterns were compared, there was no consistency in the magnitude of the increase between the primary and secondary rise. For example, when progestagen concentrations were averaged across years within females, mean urinary progestagen during the secondary rise was threefold higher compared to the primary rise interval $(88.6 \pm 9.4$ vs $27.4 \pm 1.1 \mathrm{ng} / \mathrm{mg}$ creatinine $(\mathrm{Cr}))$, whereas mean faecal progestagen was sevenfold higher during the secondary versus primary rise $(5048.3 \pm 853.3$ vs $733.8 \pm 37.0 \mathrm{ng} / \mathrm{g}$ ). For SB452, the mean urinary progestagen concentration was sevenfold higher during the secondary than primary rise $(116.9 \pm 13.2$ vs 16.7 $\pm 0.6 \mathrm{ng} / \mathrm{mg} \mathrm{Cr}$ ). Meanwhile, there was a threefold increase in mean faecal progestagen during the secondary compared to primary rise $(1342.7 \pm 125.6$ vs $428.5 \pm 29.7 \mathrm{ng} / \mathrm{g})$.

\section{Year-to-year faecal progestagen patterns}

When annual reproductive cycle data were averaged for each of SB473 and SB452, there was no difference $(P>0.05)$ between these individuals in durations of the primary or secondary progestagen rise or total length of the luteal phase (Table 1). The correlation between date of luteal phase onset (i.e. day after the $\mathrm{E}$ peak) and the duration of the luteal phase was also non-significant $(P>0.05)$ for both females (SB473, $r=0.08$; SB452, $r=0.10$ ). Among years, the average fold increase between the primary and secondary rise was similar within females $(P>0.05)$. For SB473, mean faecal progestagen during the primary (but not secondary) rise differed $(P<0.05)$ among all 3 years. For SB452, faecal progestagen during the primary rise in 2002 was similar $(P>0.05)$ to 2003 , but faecal progestagen for both years was lower $(P<0.05)$ compared to 2004 values. Faecal progestagen during the secondary rise was similar $(P>0.05)$ in 2002 and 2003, but concentrations for both of these years were higher $(P<0.05)$ than in 2004 . Overall, average progestagen concentrations did not differ $(P>0.05)$ between the two females during the primary or secondary phases (Table 1 ). Collectively, data indicated that the magnitude and duration of the biphasic progestagen excretion pattern were quite consistent between animals and across years within a given individual.

Table 1 Year-to-year evaluations of mean faecal progestagen concentrations ( \pm s.E.M. ng/g) and durations ( \pm s.E.M. $d)$ during the luteal phases of two adult female giant pandas.

\begin{tabular}{|c|c|c|c|c|c|c|c|c|}
\hline \multirow[b]{2}{*}{ Female } & \multirow[b]{2}{*}{ Year } & \multirow[b]{2}{*}{$\begin{array}{l}\text { Day of year of } \\
\text { oestrogen peak }\end{array}$} & \multicolumn{2}{|c|}{ Primary rise } & \multicolumn{2}{|c|}{ Secondary rise } & \multirow{2}{*}{$\begin{array}{l}\text { Fold increase } \\
\text { from primary to } \\
\text { secondary rise }\end{array}$} & \multirow[b]{2}{*}{$\begin{array}{l}\text { Total luteal } \\
\text { duration }\end{array}$} \\
\hline & & & Duration & $\begin{array}{l}\text { Progestagens } \\
\text { (ng/g) }\end{array}$ & Duration & $\begin{array}{l}\text { Progestagens } \\
\text { (ng/g) }\end{array}$ & & \\
\hline \multirow[t]{4}{*}{ SB473 } & 2002 & 117 & 109 & $424.6 \pm 16.7^{\mathrm{a}}$ & 52 & $1338.2 \pm 154.8$ & 3.2 & 161 \\
\hline & 2003 & 94 & 103 & $648.7 \pm 37.7^{\mathrm{b}}$ & 40 & $2996.8 \pm 545.5$ & 4.6 & 143 \\
\hline & 2004 & 123 & 98 & $777.9 \pm 42.0^{\mathrm{C}}$ & 39 & $4536.3 \pm 821.2$ & 5.8 & 137 \\
\hline & Mean & $111.3 \pm 8.8$ & $103.3 \pm 3.1$ & $617.1 \pm 103.2$ & $43.7 \pm 4.2$ & $2957.0 \pm 923.5$ & 4.5 & $147.0 \pm 7.2$ \\
\hline \multirow[t]{4}{*}{ SB452 } & 2002 & $92--1$ & 105 & $238.7 \pm 23.8^{\mathrm{d}}$ & $42-1$ & $2583.3 \pm 662.7^{f}$ & 10.8 & 147 \\
\hline & 2003 & 84 & 61 & $369.4 \pm 38.8^{\mathrm{d}}$ & 64 & $2548.2 \pm 382.9^{f}$ & 6.9 & 125 \\
\hline & 2004 & 74 & 95 & $427.3 \pm 30.4^{\mathrm{e}}$ & 53 & $1342.7 \pm 125.6^{\mathrm{g}}$ & 3.1 & 148 \\
\hline & Mean & $83.8 \pm 5.2$ & $87.0 \pm 13.3$ & $345.1 \pm 55.8$ & $53.0 \pm 6.4$ & $2158.1 \pm 407.8$ & 7.0 & $140.0 \pm 7.5$ \\
\hline
\end{tabular}

Progestagen concentrations within reproductive state within females with different subscripts differ $(P<0.05)$. 


\section{Faecal progestagen patterns in non-parturient giant pandas}

Faecal $E$ and progestagen excretion profiles for four representative, non-parturient females are presented in Fig. 3. For these individuals, mean progestagen concentrations for the 50-day period after the E surge were 89.7-318.5 ng/g greater than progestagen concentrations during the 50 days before oestrus. The primary rise in faecal progestagen averaged $416.6 \pm 122.0 \mathrm{ng} / \mathrm{g}$ and lasted $85.8 \pm 15.4$ days, whereas the secondary rise in progestagen averaged $3173.8 \pm 650.3 \mathrm{ng} / \mathrm{g}$ and lasted $42.3 \pm 5.4$ days.

\section{Faecal progestagen patterns in parturient giant pandas}

Longitudinal faecal progestagen profiles for representative giant pandas that were mated and/or $\mathrm{Al}$ and then gave birth are provided in Fig. 4. For this cohort, faecal progestagen concentrations for the 50-day period post-E peak were 36.3-300.5 ng/g greater than during the 50 -day pre-E surge interval. The duration of the primary rise averaged $83.5 \pm 9.5$ days during which time faecal progestagen averaged $286.3 \pm 124.4 \mathrm{ng} / \mathrm{g}$, whereas the secondary rise in progestagen averaged 2574.4 $\pm 568.8 \mathrm{ng} / \mathrm{g}$ and lasted $36.8 \pm 2.2$ days. Within this specific 'pregnancy group', two dams gave birth to singletons (SB446 and SB473) and two to twins (SB487 and SB414). Mean faecal progestagen concentrations in twinning dams $(622.8 \pm 182.3 \mathrm{ng} / \mathrm{g})$ actually were lower $(P<0.05)$ than females producing singleton cubs $(1331.8 \pm 208.8 \mathrm{ng} / \mathrm{g})$. For all giant pandas that gave birth $(n=11)$, average durations of the primary and secondary progestagen rise intervals were 80.5 \pm 3.9 days (range, 61-104 days) and 38.8 \pm 3.0 days (range, 26-55 days) respectively (total luteal phase duration, $121.5 \pm 4.4$ days). Length of gestation (calculated on the basis of date of first breeding or $\mathrm{Al}$ event to parturition) ranged from days 191 to 273 (mean, $228.7 \pm 9.2$ days).

\section{Faecal progestagens in parturient versus non-parturient individuals}

Progestagen data were compared between giant pandas that did or did not give birth. Faecal progestagen concentrations were higher $(P<0.05)$ in non-parturient females compared to parturient females during both primary ( $460.9 \pm 28.0$ vs $291.0 \pm 20.9 \mathrm{ng} / \mathrm{g}$ respectively) and secondary $(3125.5 \pm 339.4$ vs $3096.5 \pm 455.3 \mathrm{ng} / \mathrm{g}$ respectively) rise intervals. The magnitude of the average increase in faecal progestagen from the primary to the secondary rise was similar $(P>0.05)$ for non-parturient $(6.0 \pm 2.5$-fold) and parturient (11.7 \pm 6.5 -fold) females. Likewise, the durations of the primary (parturient, $82.3 \pm 8.4$ days versus non-parturient, $95.5 \pm 10.0$ days) and secondary (parturient, $36.8 \pm 2.2$ days versus nonparturient, $42.3 \pm 5.4$ days) rise intervals were similar $(P>0.05)$. As a result, there were no differences $(P>0.05)$ in the overall length of the biphasic interval of elevated progestagen excretion (parturient, 119.0 \pm 7.4 days versus non-parturient, $137.8 \pm 12.8$ days).

Co-chromatographic profiles depicting faecal progestagen immunoreactivity after high pressure liquid chromatography (HPLC) separation from two parturient (SB414 and SB446) and two non-parturient (SB473, 2002; SB452, 2003) females are presented in Fig. 5. Correlation between the two data sets was significant $(r=0.84 ; \quad P<0.05)$. Broad immunoreactive peaks (fractions 4-13) that co-eluted with pregnanediol glucuronide were detected in all individuals. Additionally, a broad band of immunoreactivity (fractions 63-80)

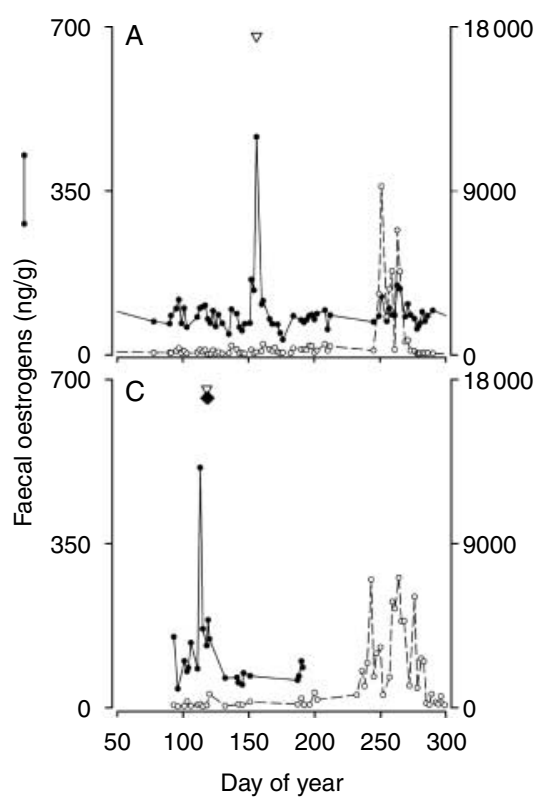

Reproduction (2010) 140 183-193

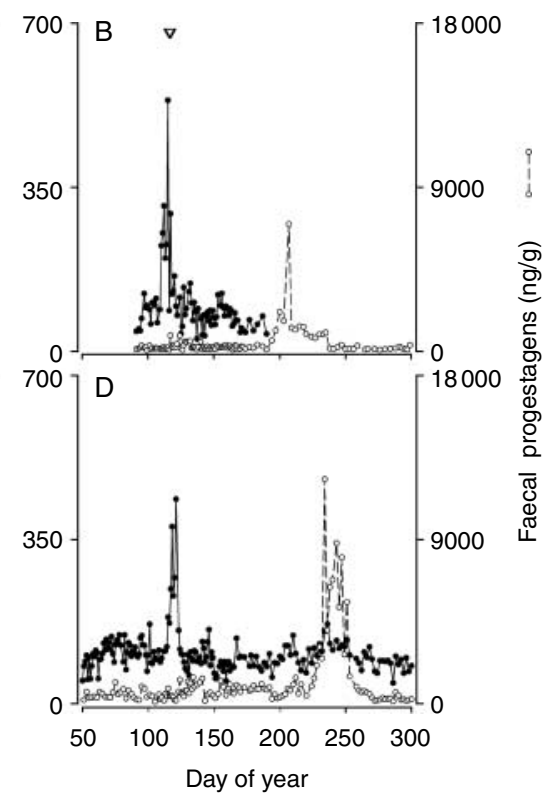

Figure 3 Representative profiles of faecal oestrogen (closed circles, solid lines) and progestagen (open circles, dashed lines) metabolites of non-parturient females (A) SB414, (B) SB544, (C) SB490 and (D) SB473. Open triangles denote days of natural breeding, and the closed diamonds represent days of artificial insemination. All data are aligned day of year. 

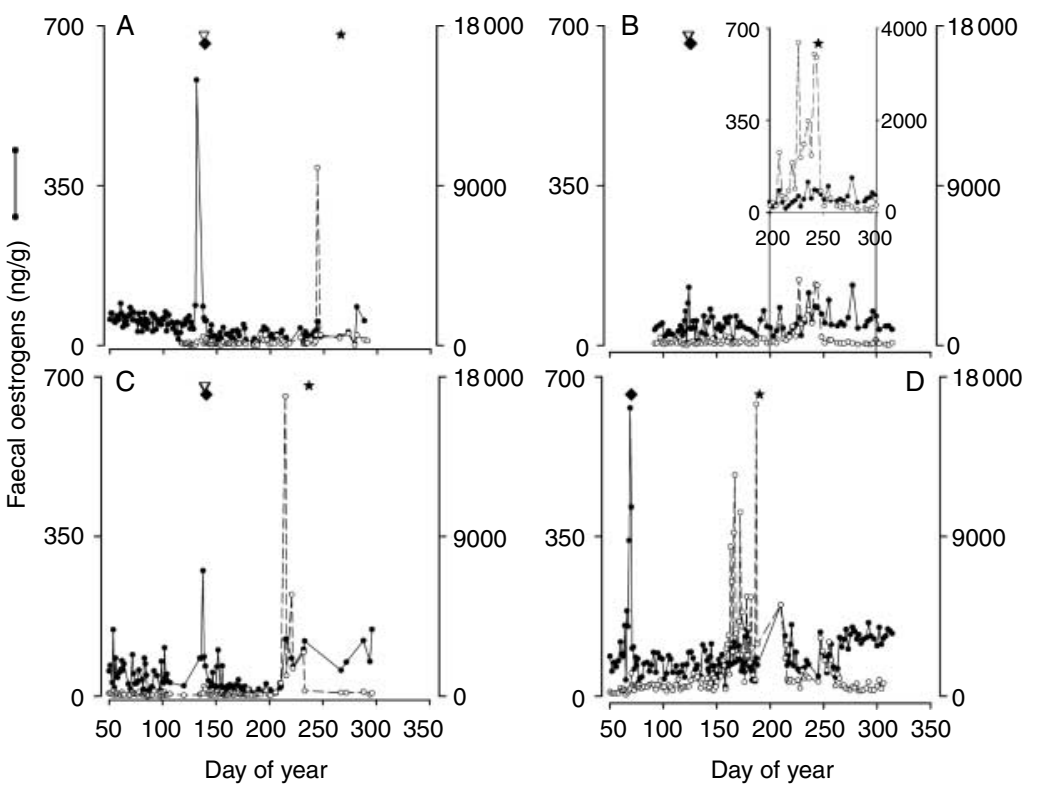

Figure 4 Representative profiles of faecal oestrogen (closed circles, solid lines) and progestagen (open circles, dashed lines) metabolites of parturient females (A) SB446, (B) SB487, (C) SB414 and (D) SB473. Open triangles denote days of natural breeding, closed diamonds indicate days of artificial insemination and closed stars mark the day of parturition. All data are aligned to the day of year. Scale of inset graph (profile B) illustrates the variability in peak progestagen excretion among females. co-eluted in the range of ${ }^{3} \mathrm{H}-\mathrm{P}_{4}$ (fraction 66). At least, six additional unidentified immunoreactive peaks (fractions 20-60) were detected in both parturient and non-parturient females. Overall, the spectrum of immunoreactive progestagens was indistinguishable in both parturient and non-parturient females.

\section{Faecal progestagens in acyclic giant pandas}

Ten acyclic profiles in our study were characterized by the absence of a faecal E surge, sexual behaviours and a sustained increase in faecal progestagen excretion (representative individuals in Fig. 6). All of these females were of reproductive age (5-12 years), and five of ten had given birth earlier (including SB382, Fig. 6C), although none were nursing cubs during the year of assessment. Faecal progestagen in acyclic giant pandas $(101.9 \pm 4.5 \mathrm{ng} / \mathrm{g})$ was lower $(P<0.05)$ than baseline concentrations in non-parturient $(295.1 \pm 21.2 \mathrm{ng} / \mathrm{g})$ or parturient $(142.9 \pm 10.5 \mathrm{ng} / \mathrm{g})$ females.

\section{Discussion}

This study demonstrated that ovulating giant pandas experienced a protracted, biphasic increase in progestagen production that was detectable by longitudinal analysis of hormonal metabolites excreted in freshly voided faeces. The excretion pattern was unusual in that an initial progestagen rise early after ovulation was sustained for a variable interval that lasted 61-122 days. This interval was then followed by a distinctive 3- to 20-fold elevation that lasted another 28-63 days before declining to signal birth or the end of a non-parturient phase. A general biphasic progestagen pattern has been reported from earlier urinary monitoring studies of this species, but only in a few individuals
(Hodges et al. 1984, Chaudhuri et al. 1988, Masui et al. 1989, Monfort et al. 1989, Mainka et al. 1990, McGeehan et al. 2002, Narushima et al. 2003). The present study was important because of the increased confidence generated from simultaneously examining a large cohort of giant pandas, some of which were observed year to year. Doing so permitted careful examination of the relatively modest, yet significant primary progestagen rise that characterized the immediate post-oestrual interval, even in unmated females. This finding confirmed previous assertions by others (Monfort et al. 1989, Mainka et al. 1990, Steinman et al. 2006, Spady et al. 2007) that luteal formation was spontaneous and obligate in this species. Whereas the duration of the initial progestagen rise varied highly among individuals and across years, we found great consistency in the magnitude and duration of the shorter, hyperelevated secondary hormonal rise. Understanding the

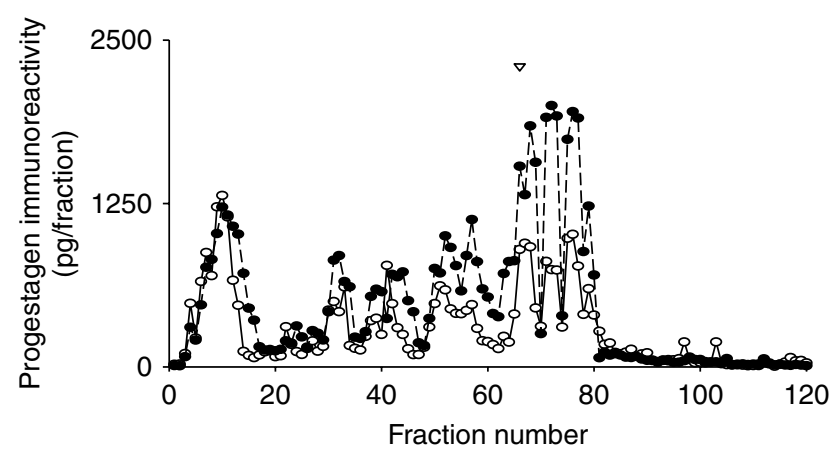

Figure 5 Co-chromatographic profiles depicting faecal progestagen immunoreactivity after HPLC separation from two parturient (open circles, solid lines) and two non-parturient (closed circles, dashed lines) females. Triangle indicates peak elution of ${ }^{3} \mathrm{H}-\mathrm{P}_{4}$ (fraction 66) that was added as a co-chromatographic marker to both faecal pools before HPLC analysis. 

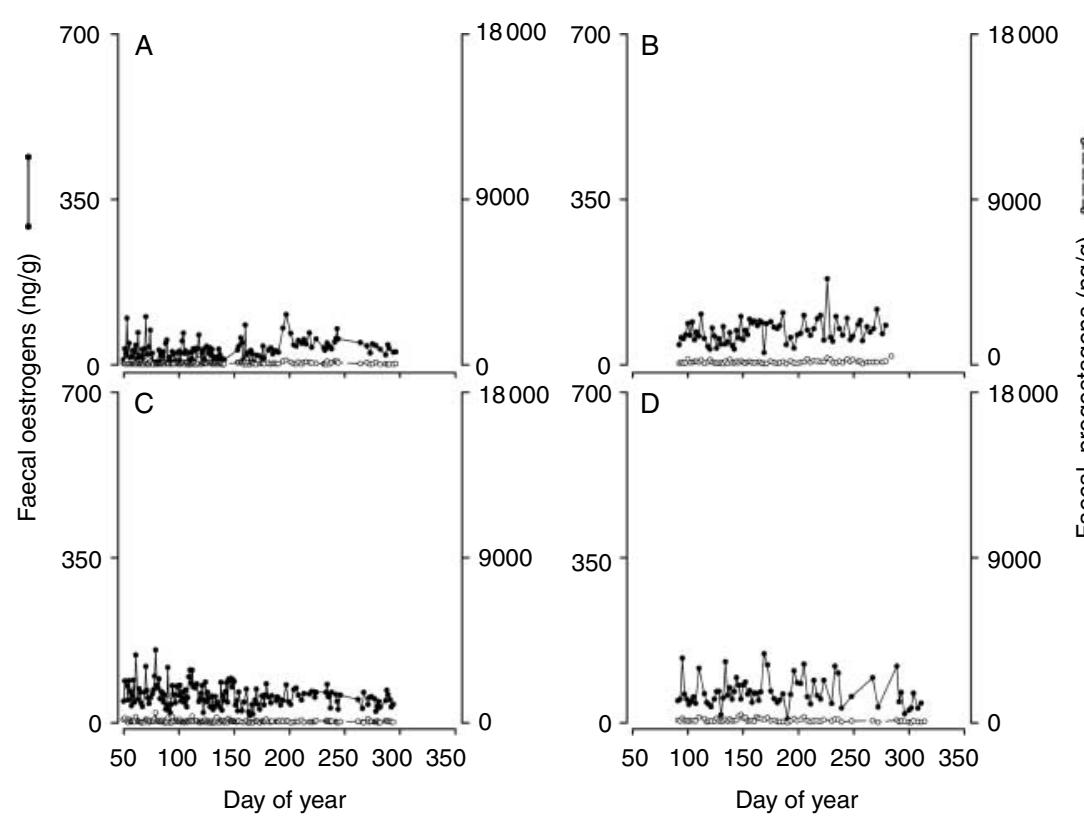

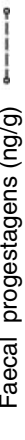

Figure 6 Representative profiles of faecal oestrogen (closed circles, solid lines) and progestagen (open circles, dashed lines) metabolites of acyclic females (A) SB439, (B) SB474, (C) SB382 and (D) SB495. All data are aligned to day of year. Scales for faecal oestrogen and progestagen concentrations and day of year are the same as presented in Figs 3 and 4. mechanisms associated with this accelerated increase in progestagen excretion and its potential association with implantation offers rich opportunities for further research. This was especially evident given that it was possible to track both subtle and marked fluctuations in progestagen excreted in faeces, a biomaterial that is much easier to recover than blood or urine.

A two-tiered, post-ovulatory progestagen rise has been noted in previous studies of the giant panda (reviewed in Steinman et al. (2006)). However, ours was the first effort to differentially quantify the duration, amplitude and temporal excretion patterns between the two phases and across a large cohort of pregnant versus non-pregnant individuals of this rare species. The post-ovulatory biphasic progestagen profiles for the giant panda generally were highly consistent with findings in other ursids (American black bear; Foresman \& Daniel 1983, Palmer et al. 1988, Hellgren et al. 1991, Tsubota et al. 1998, Schulz et al. 2003; brown bear; Tsubota et al. 1992; spectacled bear, Tremarctos ornatus; Dehnhard et al. 2006; Asiatic black bear; Sato et al. 2001) as well as mustelids (mink; Murphy \& Moger 1977, Allais \& Martinet 1978, Papke et al. 1980; European badger; Canivenc \& Bonnin 1981; western spotted skunk; Mead 1981). This includes earlier suggestions that the duration of the secondary phase is less variable than that of the primary phase (Enders 1952, Murphy \& Moger 1977, Allais \& Martinet 1978, Papke et al. 1980, Canivenc \& Bonnin 1981, Mead 1981, Foresman \& Daniel 1983). Enders (1952) first postulated that the second, enhanced $\mathrm{P}_{4}$ rise was associated with implantation of a previously free-floating embryo, a concept later proven for the mink (Allais \& Martinet 1978, Murphy et al. 1993, Douglas et al. 1998), European badger (Canivenc \& Bonnin 1981, Yamaguchi et al. 2006) and spotted skunk (Mead 1981). What is much less well understood is the mechanism(s) responsible for provoking this significant $\mathrm{P}_{4}$ surge. Early morphological studies in several carnivore species have revealed that corpora lutea $(\mathrm{CL})$ form rapidly post-ovulation and remain unchanged until lutein cells increase in size, change in cellular ultrastructure and secrete more progestagens coincident with implantation (Wimsatt 1963, Mead 1986, Douglas et al. 1998). An intriguing area for future research is determining how $C L$ rejuvenation or enhancement is mediated and whether an extra-gonadal source of steroid contributes to the hormonal milieu associated with the secondary progestagen rise. Regardless, we speculate that conceptus presence has little impact on $C L$ function because faecal progestagen profiles were unremarkable between parturient and non-parturient giant pandas.

Seasonality is a dominant characteristic of the giant panda's ovarian cycle (Steinman et al. 2006) and is likely one of the primary cues responsible for modulating embryonic diapause in the species (Sandell 1990, Zhang et al. 2009). Although the breeding season is distinct (February to June), we learned in the present study that there are year-to-year variations in seasonal oestrus onset within the same animal. One might expect early seasonal oestrus to be followed by a prolonged luteal phase (i.e. to optimize the timing of nidation, parturition and offspring survival), yet we found no evidence for such a mechanism. In fact, for two females monitored sequentially over multiple years, the duration and magnitude of the luteal phase were remarkably consistent, regardless of when oestrus occurred. However, our sample size was small, and more work is needed to determine whether the duration of the luteal phase adjusts relative to the seasonal timing of ovulation.

Our findings were also relevant to the topic of pseudopregnancy. We intentionally avoided using the term pseudopregnancy because it became apparent that 
giant pandas can exhibit a protracted biphasic progestagen profile after ovulation and in the absence of copulation and any direct male contact. Secondly, and perhaps more importantly, giant pandas may be experiencing significant embryonic loss, with many females previously classified as 'pseudopregnant' actually undergoing failed pregnancies (Steinman et al. 2006). For example, Sutherland-Smith et al. (2004) documented two foetuses during late gestation (day 134) via ultrasound in a female that later gave birth to a single cub (day 150). Anecdotal reports of suspicious foetal loss via ultrasonographic examinations have also been noted at the Smithsonian's National Zoological Park (S Murray, personal communications) and Memphis Zoo (A J Kouba, personal communications). Post-nidation foetal loss has also been well documented in the European badger, another delayed implanting species (Cresswell et al. 1992, Yamaguchi et al. 2006). Giant pandas clearly experience true pseudopregnancy in the absence of mating or conception, including displaying strong maternal behaviours (e.g. decreased appetite, nest building and cradling inanimate objects; Steinman et al. 2006) during the waning days of the secondary progestagen phase. However, because it is impossible to discriminate pregnant from non-pregnant individuals using excreted steroids (either urine or, as we have discovered here, faeces), we contend that it is more accurate to retrospectively classify giant panda reproductive cycles as 'parturient' versus 'non-parturient'.

The gestation length derived from this study (121.5 \pm 4.4 days; range, $99-145$ days) was within the 85-185 days previously reported for this species (Zhu et al. 2001). Our systematic efforts to document the excretory dynamics of the luteal phase revealed an invariant pattern in progestagen excretion between parturient and non-parturient females, which was not unusual. Within the order Carnivora, progestagen profiles are indistinguishable in the pregnant versus non-pregnant domestic dog (Canis familiaris; Smith \& McDonald 1974, Concannon et al. 1975), red wolf (Canis rufus; Walker et al. 2002), maned wolf (Chrysocyon brachyurus; Velloso et al. 1998, Songsasen et al. 2006), bush dog (Speothos venaticus; DeMatteo et al. 2006), wolverine (Gulo gulo; Mead et al. 1993), black-footed ferret (Mustela nigripes; Brown 1997) and dwarf mongoose (Helogale parvula; Creel et al. 1991). In the case of the giant panda, this similarity extended to a homologous milieu of immunoreactive progestagen metabolites (detected by co-chromatographic HPLC analysis) that were indistinguishable between parturient and non-parturient females.

The topic of acyclicity in the giant panda has not been previously addressed. Some females have been classified by animal managers as experiencing 'weak oestrus' because of the lack of behavioural signs of sexual receptivity and failed ability to breed or conceive to copulation or Al (Shuling et al. 1997). Some cattle are known to experience 'silent ovulation', another form of weak oestrus (Allrich 1994). Of the 30 reproductive events evaluated in giant pandas of our study, 10 (31.3\%) were accompanied by the absence of or diminished sexual behaviour. Additionally, all of these individuals failed to produce an oestrogen surge or rise in progestagen throughout the year. Therefore, rather than finding data to support the concept for 'weak oestrus', it was apparent that certain females were completely acyclic and non-ovulatory. In nature, giant pandas generally produce cubs every other year because of lactational suppression related to a maternal care interval lasting up to 18 months (Zhu et al. 2001). In China, cubs born in captivity usually are weaned at 6 months of age, thereby allowing the female to recycle, mate and produce additional offspring the next year. Because six of ten giant panda females experiencing acyclicity in our study had given birth the previous year, we speculate that some period of anoestrus may be an obligate feature of the giant panda's life history that helps to maximize reproductive fitness.

Aside from providing new scholarly insight, our findings have potential management implications. For years, a compliment of non-invasive tools has been used to approximate the reproductive status of female giant pandas in ex situ collection, including through behavioural observations (Czekala et al. 1998, McGeehan et al. 2002), urinary hormone quantification (Steinman et al. 2006), visual changes of the vulva (McGeehan et al. 2002), vaginal cytology (Durrant et al. 2006) and/or ultrasonography in cooperative individuals (Sutherland-Smith etal. 2004, Zhang et al. 2009). Urinary progestagen monitoring has been especially useful for tracking pregnancy (or pseudopregnancy) of captive mated and/or artificially inseminated females. Because it is currently not feasible to diagnose pregnancy, a return to baseline progestagen concentrations has been used to signal either an impending birth or the ending of a 'pregnancy watch', both of which influence the use of zoological resources (Steinman et al. 2006). Similarly, faecal steroid measures may prove useful for assessing reproductive status in free-living giant pandas. Although giant pandas are rarely observed in the wild, females generally sustain a given territory (Schaller et al. 1985), and encountering giant panda faeces in the field can be common. If two to three relatively fresh faecal samples were collected over a 1- to 2-week interval, it would be possible to estimate reproductive status of a free-living female, including determining whether a given female was post-ovulatory or potentially pregnant.

\section{Materials and Methods}

\section{Study animals and facilities}

Two adult giant pandas were studied in separate North American zoos. An additional 12 adult females from a captive breeding centre in China were also monitored. 
In several animals over the course of 2 and 3 years, 10 acyclic, 11 parturient and 9 non-parturient phases were analysed. All biomaterials (urine and faeces) were collected non-invasively during routine animal care of unrestrained animals. Research and management procedures (including $\mathrm{Al}$ ) were reviewed and approved by the respective Institutional Animal Care and Use Committees of SNZP and ZA.

\section{North America}

The giant pandas living in the two North American institutions were intensively monitored on a year-to-year basis. Female SB473 (3.5 year old at study onset) was maintained at the SNZP $\left(39^{\circ} \mathrm{N}, 77^{\circ} \mathrm{W}\right)$ and monitored in 2002, 2003, 2004 and 2005, whereas SB452 (4.5 years) was evaluated in 2002, 2003 and 2004 at ZA $\left(33^{\circ} \mathrm{N}, 84^{\circ} \mathrm{W}\right)$. Females were managed as previously described (Kersey et al. 2010), and records were maintained on sexual behaviours (McGeehan et al. 2002), dates of attempted or confirmed copulations and/or Als and parturition.

\section{China}

Study animals (12 females; age range, 4-16 years) were from the China Conservation and Research Centre for the Giant Panda at the Wolong Nature Reserve $\left(31^{\circ} \mathrm{N}, 103^{\circ} \mathrm{E}\right)$. Enclosures for the females and management have been previously described (Kersey et al. 2010).

\section{Sample collection and processing}

Both urine and faecal samples were collected during years 2002, 2003 and 2004 from the adult female giant pandas maintained at SNZP and ZA to validate the consistency of progestagen pattern changes over time in these two types of excreta. Only faecal samples were collected from the animals in China.

\section{Urine}

Fresh urine was collected (3-7 days/week) after being aspirated, usually from the concrete floor of an enclosure, and then stored frozen $\left(-20{ }^{\circ} \mathrm{C}\right)$ in labelled and sealed $12 \times 75 \mathrm{~mm}$ plastic tubes until analysis. Urine was collected in the morning, but later in the day if unavailable earlier. Urine samples excreted during evening/night hours were marked as 'overnight' specimens and assigned an excretion time of $0000 \mathrm{~h}$.

To account for variations in water content, each urine sample was indexed for Cr (Taussky 1954, Monfort et al. 1989). Urine samples with a $\mathrm{Cr}$ mass $<0.1 \mathrm{mg} \mathrm{Cr} / \mathrm{ml}(\sim 7 \%$ of all samples) were considered too dilute and were excluded from hormonal metabolite analyses. Hormone masses $(\mathrm{ng} / \mathrm{ml})$ were divided by $\mathrm{Cr}$ concentration $(\mathrm{mg} / \mathrm{ml})$, and final hormone values were expressed as mass of hormone per $\mathrm{mg}$ of excreted $\mathrm{Cr}$ (ng/mg Cr).

\section{Faeces}

An aliquot of freshly voided (within $1 \mathrm{~h}$ ) faeces that visibly contained the least amount of undigested bamboo was collected 3-7 days/week from all adult females. Annual sampling began on 1 February and ended by 4 weeks after parturition or the non-parturient interval. Each sample was placed in a labelled, resealable plastic bag, and stored at $-20{ }^{\circ} \mathrm{C}$ until shipped frozen by air transport to our laboratory for processing and extraction, as previously described (Kersey et al. 2010).

\section{Steroid enzyme immunoassays}

Faecal E metabolites were quantified using a single antibody oestrone glucuronide enzyme immunoassay (EIA; Stabenfeldt et al. 1991, Kersey et al. 2010). Inter-assay coefficients of variation $(\mathrm{CV})$ for two internal controls ( $n=83$ assays) were $14.5 \%$ (mean binding, $40.0 \%$ ) and $14.9 \%$ (mean binding, $74.2 \%$ ), and intra-assay CV was $<10 \%$.

Progestagen concentrations for urine and faeces were determined with a single antibody $\mathrm{P}_{4}$ EIA (Graham et al. 2001, Kersey et al. 2010). Inter-assay CV for two internal controls ( $n=104$ assays) were $14.3 \%$ (mean binding, 39.0\%) and $14.6 \%$ (mean binding, $71.2 \%$ ), and intra-assay CV was $<10 \%$.

\section{High pressure liquid chromatography}

Reverse phase HPLC (Varian ProStar; Varian Analytical Instruments, Walnut Creek, CA, USA) was used to identify progestagen metabolites in the faecal extracts (Monfort et al. 1997). Pooled sample extracts that contained high progestagen concentrations from parturient $(n=2 ; 1 \mathrm{ml}$ of three samples from each female) and non-parturient females $(n=2 ; 1 \mathrm{ml}$ of three samples from each female) were concentrated 20-fold and spiked with ${ }^{3} \mathrm{H}-\mathrm{P}_{4}(\sim 14000$ c.p.m./ml $)$ to act as a co-chromatographic marker. After separation using a reverse phase C18 HPLC column (Varian Analytical Instruments), collected fractions were quantified for radioactivity to identify marker elution times. Fractions then were dried, resuspended in $0.3 \mathrm{ml}$ of buffer and assayed via the $\mathrm{P}_{4}$ ElA to detect fraction immunoreactivity alongside radioactive marker elution times to identify predominate steroidal metabolites.

\section{Statistical analysis}

Baseline faecal progestagen excretion during the anoestrual phase of the reproductive cycle was determined using an iterative process (Moreira et al. 2001). Luteal phase onset was considered the day after the preovulatory E peak. The end of the luteal phase was designated as the first day that progestagen concentrations returned to baseline range (baseline mean \pm double s.D.) for two or more consecutive days. The subset of samples constituting the luteal phase was evaluated using an iterative process to eliminate faecal hormone concentration outliers that exceeded 2 s.D. of the mean. Duration of the primary progestagen rise was defined as the time from the initial discernible increase to an elevation 2 s.D. above the mean for at least two consecutive days. Length of the 
secondary rise was considered as the interval from the end of the primary rise to the termination of the luteal phase. All hormonal metabolite concentrations and interval durations were expressed as mean \pm s.E.M.

For statistical comparisons, urinary and faecal progestagen was aligned to the urinary E peak. For all other faecal hormone analyses, data were adjusted to day of year (i.e. 1 January $=$ day 1). Relatedness between concomitant urinary and faecal progestagen concentrations as well as between HPLC analyses of parturient versus non-parturient profiles was determined using a Pearson product moment correlation. Relation between luteal phase onset and duration was determined by linear regression analysis. All data were evaluated for normality (Kolmogorov-Smirnov test) before subsequent testing. Comparisons between dependent data were made via Student's paired $t$-test (normal) or Wilcoxon signed rank test (not normal), and independent analyses were conducted with a Mann-Whitney test (not normal). Three data sets that failed normality were examined further using the Tukey-Friedman repeated-measures ANOVA on ranks (dependent data) or with the Kruskal-Wallis ANOVA (independent data). Significance was considered at a $P$ value of $<0.05$. Iterations were evaluated in Microsoft Excel 2007 (Microsoft Inc.), and all other statistical analyses were conducted in SigmaStat 3.1 (Systat Software, Inc., Point Richmond, CA, USA).

\section{Declaration of interest}

The authors declare that there is no conflict of interest that could be perceived as prejudicing the impartiality of the research reported.

\section{Funding}

This study was funded by Friends of the National Zoo.

\section{Acknowledgements}

We thank Susan Walker, Nicole Abbondanza, Karen Steinman, Copper Aitken-Palmer, Adrienne Crosier and Nicole Presley for their logistical support. Special thanks to Nicole Savageau, Bridgette von Holdt, Jessica Beckman, Valerie Parkman, Serena Enloe and Corinna Bazlett for laboratory assistance. We also acknowledge the work of the keeper and curatorial staffs at the Smithsonian's National Zoological Park, Zoo Atlanta and China Conservation and Research Centre for the Giant Panda for sample collection.

\section{References}

Allais C \& Martinet L 1978 Relation between daylight ratio, plasma progesterone levels and timing of nidation in mink (Mustela vison). Journal of Reproduction and Fertility 54 133-136.

Allrich RD 1994 Endocrine and neural control of estrus in dairy cows. Journal of Dairy Science 77 2738-2744.

Bonney RC, Wood DJ \& Kleiman DG 1982 Endocrine correlates of behavioural oestrus in the female giant panda (Ailuropoda melanoleuca) and associated hormonal changes in the male. Journal of Reproduction and Fertility 64 209-215.
Brown JL 1997 Fecal steroid profiles in black-footed ferrets exposed to natural photoperiod. Journal of Wildlife Management 61 $1428-1436$.

Canivenc R \& Bonnin M 1981 Environemntal control of delayed implantation in the European badger (Meles meles). Journal of Reproduction and Fertility Supplement 29 25-33.

Chaudhuri M, Kleiman DG, Wildt DE, Bush M, Frank ES \& Thau RB 1988 Urinary steroid concentrations during natural and gonadotrophininduced oestrus and pregnancy in the giant panda (Ailuropoda melanoleuca). Journal of Reproduction and Fertility 84 23-28.

Conaway CH 1971 Ecological adaptation and mammalian reproduction. Biology of Reproduction 4 239-247.

Concannon PW, Hansel W \& Visek B 1975 The ovarian cycle of the bitch: plasma estrogen, LH and progesterone. Biology of Reproduction 13 112-119.

Creel SC, Monfort SL, Wildt DE \& Waser PM 1991 Spontaneous lactation is an adaptive result of pseudopregnancy. Nature 351 660-662.

Cresswell WJ, Harris S, Cheeseman CL \& Mallinson PJ 1992 To breed or not to breed: an analysis of the social and density-dependent constraints on the fecundity of female badgers (Meles meles). Philosophical Transactions of the Royal Society of London. Series B: Biological Sciences 338 393-407.

Czekala N, Lindburg D, Durrant B, Swaisgood R, He T \& Tang C 1998 The estrogen profile, vaginal cytology, and behaviour of a giant panda female during estrus. In Proceedings of the International Symposium on the Protection of the Giant Panda (Ailuropoda melanoleuca), pp 111-113. Eds A Zhang \& G He. Chengdu: Sichuan Publishing House of Science and Technology.

Dehnhard M, Hildebrandt T, Knauf T, Jewgenow K, Kolter L \& Goritz F 2006 Comparative endocrine investigations in three bear species based on urinary steroid metabolites and volatiles. Theriogenology $\mathbf{6 6}$ 1755-1761.

DeMatteo KE, Porton IJ, Kleiman DG \& Asa CS 2006 The effect of the male bush dog (Speothos venaticus) on the female reproductive cycle. Journal of Mammalogy 87 723-732.

Douglas DA, Song JH, Moreau GM \& Murphy BD 1998 Differentiation of the corpus luteum of the mink (Mustela vison): mitogenic and steroidogenic potential of luteal cells from embryonic diapause and postimplantation gestation. Biology of Reproduction 58 1163-1169.

Durrant BS, Olson MA, Anderson A, Gual-Sil F, Li D \& Huang Y 2006 The value and significance of vaginal cytology. In Giant Pandas: Biology, Veterinary Medicine and Management, pp 231-244. Eds DE Wildt, A Zhang, Z Zhang, DL Janssen \& S Ellis. Cambridge: Cambridge University Press.

Ellis S, Pan W, Xie Z \& Wildt DE 2006 The giant panda as a social, biological and conservation phenomenon. In Giant Pandas: Biology, Veterinary Medicine and Management, pp 1-16. Eds DE Wildt, A Zhang, Z Zhang, DL Janssen \& S Ellis. Cambridge: Cambridge University Press.

Enders RK 1952 Reproduction in the mink (Mustela vison). Proceedings of the American Philosophical Society 96 691-755.

Erskine MS 1998 Pseudopregnancy. In Encyclopedia of Reproduction, pp 120-124. Eds E Knobil \& JD Neill. San Diego, CA: Academic Press.

Foresman KR \& Daniel JC 1983 Plasma progesterone concentrations in pregnant and non-pregnant black bears (Ursus americanus). Journal of Reproduction and Fertility 68 235-239.

Graham L, Schwarzenberger F, Mostel E, Galama W \& Savage A 2001 $A$ versatile enzyme immunoassay for the determination of progestogens in feces and serum. Zoo Biology 20 227-236.

Hamlett GWD 1935 Delayed implantation and discontinuous development in the mammals. Quarterly Review of Biology $10432-447$.

Hellgren EC, Vaughan MR, Gwazdauskas FC, Williams B, Scalon PF \& Kirkpatrick RL 1991 Endocrine and electrophoretic profiles during pregnancy and nonpregnancy in captive female black bears. Canadian Journal of Zoology 69 892-898.

Hodges JK, Bevam DJ, Celm M, Hearn JP, Jones DM, Kleiman DG, Knight JA \& Moore HDM 1984 Aspects of the reproductive endocrinology of the female giant panda (Ailuropoda melanoleuca) in captivity with special reference to the detection of ovulation and pregnancy. Journal of Zoology 203 253-267. 
Howard J, Huang Y, Wang P, Li D, Zhang G, Hou R, Zhang Z, Durrant BS, Spindler RE, Zhang H, et al. 2006 Role and efficiency of artificial insemination and genome resource banking. In Giant Pandas: Biology, Veterinary Medicine and Management, pp 469-494. Eds DE Wildt, A Zhang, Z Zhang, DL Janssen \& S Ellis. Cambridge: Cambridge University Press.

Kersey DC, Wildt DE, Brown JL, Snyder RJ, Huang Y \& Monfort SL 2010 Endocrine milieu of periestrus in the giant panda (Ailuropoda melanoleuca) as determined by noninvasive hormone measures. Reproduction, Fertility, and Development [in press].

Lindenfors P, Dalèn L \& Angerbjörn A 2003 The monophyletic origin of delayed implantation in carnivores and it's implications. Evolution $\mathbf{5 7}$ 1952-1956.

Mainka SA, Cooper RM, Mao L \& Guanlu Z 1990 Urinary hormones in two juvenile female giant pandas (Ailuropoda melanoleuca). Journal of Zoo and Wildlife Medicine 21 334-341.

Masui M, Hiramatsu H, Nose N, Nakazato R, Sagawa Y, Tajima H \& Saito K 1989 Successful artificial insemination in the giant panda (Ailuropoda melanoleuca) at Ueno Zoo. Zoo Biology 8 17-26.

McGeehan L, Li X, Jackintell L, Huang S, Wang A \& Czekala NM 2002 Hormonal and behavioral correlates of estrus in captive giant pandas. Zoo Biology 21 449-466.

Mead RA 1981 Delayed implantation in mustelids, with special emphasis on the spotted skunk. Journal of Reproduction and Fertility Supplement 29 11-24.

Mead RA 1986 Role of the corpus luteum in controlling implantation in mustelid carnivores. Annals of the New York Academy of Sciences $\mathbf{4 7 6}$ 25-35.

Mead RA 1989 The physiology and evolution of delayed implantation in carnivores. In Carnivore Behavior, Ecology and Evolution, pp 437-464. Ed. JL Gittleman. Ithaca, NY: Cornell University Press.

Mead RA, Bowles M, Starypan G \& Jones M 1993 Evidence for pseudopregnancy and induced ovulation in captive wolverines (Gulo gulo). Zoo Biology 12 353-358.

Monfort SL 2003 Non-invasive endocrine measures of reproduction and stress in wild populations. In Reproduction and Integrated Conservation Science, pp 147-165. Eds WV Holt, AR Pickard, JC Rodger \& DE Wildt. Cambridge: Cambridge University Press.

Monfort SL, Dahl KD, Czekala NM, Stevens L, Bush M \& Wildt DE 1989 Monitoring ovarian function and pregnancy in the giant panda (Ailuropoda melanoleuca) by evaluating urinary bioactive FSH and steroid metabolites. Journal of Reproduction and Fertility 85 203-212.

Monfort SL, Wasser SK, Mashburn KL, Burke M, Brewer BA \& Creel SR 1997 Steroid metabolism and validation of noninvasive endocrine monitoring in the African wild dog (Lycaon pictus). Zoo Biology 16 533-548.

Moreira N, Monterio-Filho ELA, Moraes W, Swanson WF, Graham LH, Pasquali OL, Gomes MLF, Morais RN, Wildt DE \& Brown JL 2001 Reproductive steroid hormones and ovarian activity in felids of the Leopardus genus. Zoo Biology 20 103-116.

Murphy BD \& Moger WH 1977 Progestins of mink gestation: the effects of hypophysectomy. Endocrine Research Communications 4 45-60.

Murphy BD, Rajkumar K, Gonzalez-Reyna A \& Silversides DW 1993 Control of luteal function in the mink (Mustela vison). Journal of Reproduction and Fertility Supplement 47 181-188.

Narushima E, Hayashi Y, Hara T, Nose N \& Komiya T 2003 Changes in urinary concentrations of total estrogen and pregnanediol in a female giant panda (Ailuropoda melanoleuca) from 1991 to 2000. Zoo Biology 22 383-387.

Palmer SS, Nelson RA, Ramsay MA, Stirling I \& Bahr JM 1988 Annual changes in serum sex steroid in male and female black (Ursus americanus) and polar (Ursus maritimus) bears. Biology of Reproduction 38 1044-1050.

Papke RL, Concannon PW, Travis HF \& Hansel W 1980 Control of luteal function and implantation in the mink by prolactin. Journal of Animal Science 50 1102-1107.

Renfree MB \& Calaby JH 1981 Background to delayed implantation and embryonic diapause. Journal of Reproduction and Fertility Supplement 29 1-9.
Sandell M 1990 The evolution of seasonal delayed implantation. Quarterly Review of Biology $6523-42$.

Sato M, Tsubota T, Komatsu T, Watanabe G, Taya K, Murase T, Kita I \& Kudo T 2001 Changes in sex steroids, gonadotropins, prolactin, and inhibin in pregnant and nonpregnant Japanese black bears (Ursus thibetanus japonicus). Biology of Reproduction $\mathbf{6 5}$ 1006-1013.

Schaller G, Jinchu H, Wenshi P \& Jing Z 1985 The Giant Pandas of Wolong. Chicago, IL: University of Chicago Press.

Schulz LC, Nelson RA, Pyter LM \& Bahr JM 2003 Induction of pseudopregnancy in the American black bear (Ursus americanus). Journal of Experimental Zoology 298A 162-166.

Schwartz MK \& Monfort SL 2008 Genetic and endocrine tools for carnivore surveys. In Noninvasive Survey Methods for North American Carnivores, pp 228-250. Eds RA Long, P MacKay, JC Ray \& WL Zielinski. Washington, DC: Island Press.

Schwarzenberger F, Fredriksson G, Schaller K \& Kolter L 2004 Fecal steroid analysis for monitoring reproduction in the sun bear (Helarctos malayanus). Theriogenology 62 1677-1692.

Shuling Z, Zhao Q, Zhong X, Wildt D \& Seal U 1997 Report of the giant panda captive management planning workshop, Chengdu, China, 1996. In IUCN-World Conservation Union/SSC Conservation Breeding Specialist Group, p 266. Eds Z Shuling, Q Zhao, X Zhong, DE Wildt \& US Seal. Apple Valley, MN: IUCN.

Smith MS \& McDonald LE 1974 Serum levels of luteinizing hormone and progesterone during the estrous cycle, pseudopregnancy and pregnancy in the dog. Endocrinology 94 404-412.

Snyder RJ, Lawson DP, Zhang A, Zhang Z, Luo L, Zhong W, Huang X, Czekala NM, Bloomsmith MA, Forthman DL, et al. 2004 Reproduction in giant pandas. In Giant Pandas: Biology and Conservation, pp 125-132. Eds DG Lindburg \& K Baragona. Berkeley, CA: University California Press.

Songsasen N, Rodden M, Brown JL \& Wildt DE 2006 Patterns of fecal gonadal hormone metabolites in the maned wolf (Chrysocyon brachyurus). Theriogenology 66 1743-1750.

Spady TJ, Lindburg DG \& Durrant BS 2007 Evolution of reproductive seasonality in bears. Mammal Review 37 21-53.

Stabenfeldt GH, Daels PF, Munro CJ, Kindahl H, Huges JP \& Lasley B 1991 An oestrogen conjugate enzyme immunoassay for monitoring pregnancy in the mare: limitations of the assay between days 40 and 70 of gestation. Journal of Reproduction and Fertility Supplement $4 \mathbf{4}$ $37-44$.

Steinman K, Monfort SL, McGeehan L, Kersey D, Gual-Sil F, Snyder R, Wang P, Nakao T \& Czekala N 2006 Endocrinology of the giant panda and application of hormone technology to species management. In Giant Pandas: Biology, Veterinary Medicine and Management, pp 198-230. Eds DE Wildt, A Zhang, Z Zhang, DL Janssen \& S Ellis. Cambridge: Cambridge University Press.

Sutherland-Smith M, Morris PJ \& Silverman S 2004 Pregnancy detection and fetal monitoring via ultrasound in a giant panda (Ailuropoda melanoleuca). Zoo Biology 23 449-461.

Taussky HH 1954 A microcolormetric determination of creatine in urine by the Jaffe reaction. Journal of Biological Chemistry 208 853-861.

Tsubota T, Kanagawa H, Yamamoto K, Mano T, Yamanaka M, Kita I \& Tiba T 1992 Serum progesterone concentrations using P-EIA kit in captive and free-ranging Hokkaido brown bears (Ursus arctos yesoensis). Journal of Veterinary Medical Science 54 1-5.

Tsubota T, Howell-Skalla L, Boone WR, Garshelis DL \& Bahr JM 1998 Serum progesterone, estradiol, luteinizing hormone and prolactin profiles in the female black bear (Usus americanus). Animal Reproduction Science 53 107-118.

Velloso AL, Wasser SK, Monfort SL \& Dietz JM 1998 Longitudinal fecal steroid excretion in maned wolves (Chrysocyon brachyurus). General and Comparative Endocrinology 112 96-107.

Walker SL, Waddell WT \& Goodrowe KL 2002 Reproductive endocrine patterns in captive female and male red wolves (Canis rufus) assessed by fecal and serum hormone analysis. Zoo Biology 21 321-335.

Weir BJ \& Rowlands IW 1973 Reproductive strategies of mammals. Annual Review of Ecology and Systematics 4 139-163. 
Wimsatt WA 1963 Delayed implantation in the Ursidae, with particular reference to the black bear (Ursus americanus pallus). In Delayed Implantation, pp 49-76. Ed. AC Enders. Chicago: The University of Chicago Press.

Yamaguchi N, Dugdale HL \& MacDonald DW 2006 Female receptivity, embryonic diapause, and superfetation in the European badger (Meles meles): implications for the reproductive tactics of males and females. Quarterly Review of Biology 81 33-48.

Zhang H, Li D, Wang C \& Hull V 2009 Delayed implantation in giant pandas: the first comprehensive empirical evidence. Reproduction 138 979-986.
Zhu X, Lindburg DG, Pan W, Froney KA \& Wang D 2001 The reproductive strategy of giant pandas (Ailuropoda melanoleuca): infant growth and development and mother-infant relationships. Journal of Zoology 253 141-155.

Received 5 January 2010

First decision 2 February 2010

Revised manuscript received 15 April 2010

Accepted 20 April 2010 